\title{
1q21.1 microdeletion syndrome
}

INSERM

\section{Source}

INSERM. (1999). Orphanet: an online rare disease and orphan drug data base. 1 q21.1 microdeletion syndrome. ORPHA:250989

1q21.1 microdeletion syndrome is a newly described recurrent deletion syndrome with variable clinical manifestations but without the clinical picture of thrombocytopenia absent radius (TAR) syndrome. 